\title{
Lusisersily
}

\section{Dense Plasmas in Magnetic Traps: Generation of Focused Ion Beams With Controlled Ion-to-Neutral Flux Ratios}

Baranov, O., Zhong, X., Fang, J., Kumar, S., Xu, S., Cvelbar, U., Mariotti, D., \& Ostrikov, K. (2014). Dense Plasmas in Magnetic Traps: Generation of Focused Ion Beams With Controlled lon-to-Neutral Flux Ratios. IEEE Transactions on Plasma Science, 42, 2518-2519.

Link to publication record in Ulster University Research Portal

Published in:

IEEE Transactions on Plasma Science

Publication Status:

Published (in print/issue): 01/10/2014

\section{Document Version}

Publisher's PDF, also known as Version of record

\section{General rights}

Copyright for the publications made accessible via Ulster University's Research Portal is retained by the author(s) and / or other copyright owners and it is a condition of accessing these publications that users recognise and abide by the legal requirements associated with these rights.

\section{Take down policy}

The Research Portal is Ulster University's institutional repository that provides access to Ulster's research outputs. Every effort has been made to ensure that content in the Research Portal does not infringe any person's rights, or applicable UK laws. If you discover content in the Research Portal that you believe breaches copyright or violates any law, please contact pure-support@ulster.ac.uk. 


\title{
Dense Plasmas in Magnetic Traps: Generation of Focused Ion Beams With Controlled Ion-to-Neutral Flux Ratios
}

\author{
Oleg Baranov, Xiaoxia Zhong, Jinghua Fang, Shailesh Kumar, Shuyan Xu, Uroš Cvelbar, \\ Davide Mariotti, and Kostya Ostrikov
}

\begin{abstract}
Customized magnetic traps were developed to produce a domain of dense plasmas with a narrow ion beam directed to a particular area of the processed substrate. A planar magnetron coupled with an arc discharge source created the magnetic traps to confine the plasma electrons and generate the ion beam with the controlled ratio of ion-to-neutral fluxes. Images of the plasma jet patterns and numerical vizualizations help explaining the observed phenomena.
\end{abstract}

Index Terms-Arc discharge, ion beam, magnetic traps.

\section{INTRODUCTION}

$\mathbf{C}$ ONTROL of ion flows to a processed wafer is an important ability of modern nanotechnology based on low-tempertaure plasma reactors [1]. As shown experimentally, when the substrate is processed by an ion flow in the presence of a neutral component of plasma, the conditions of the surface layer formation strongly depend on the ratio $\alpha_{i n}$ of the ion flow to the neutral flow, thus allowing to obtain qualitatively new characteristics of the surface [2]-[4].

Here, we show that the control of the ion current is possible by combining different plasma sources. Producing a domain

Manuscript received November 1, 2013; revised November 26, 2013; accepted December 8, 2013. Date of publication January 14, 2014; date of current version October 21,2014. This work was supported in part by the $\mathrm{ARC}$ and in part by the National Science Foundation of China under Grant 11275127 and Grant 90923005.

O. Baranov is with the Plasma Laboratory, National Aerospace University “KhAI," Kharkov 61070, Ukraine (e-mail: olbaranov@yahoo.com).

$\mathrm{X}$. Zhong is with the Key Laboratory for Laser Plasmas, Ministry of Education, and Department of Physics and Astronomy, State Key Laboratory of Advanced Optical Communication Systems and Networks, Shanghai Jiao Tong University, Shanghai 200240, China (e-mail: xxzhong@sjtu.edu.cn).

J. Fang, S. Kumar, and K. Ostrikov are with the Plasma Nanoscience Centre Australia, CSIRO Materials Science and Engineering, Lindfield, NSW 2070, Australia (e-mail: jinghua.fang@csiro.au; shailesh.kumar@csiro.au; Kostya.Ostrikov@csiro.au).

$\mathrm{S}$. $\mathrm{Xu}$ is with the Plasma Sources and Application Center, Nanyang Technological University, Singapore 637616 (e-mail: shuyan.xu@nie.edu.sg).

U. Cvelbar is with the Jozef Stefan Institute, Ljubljana SI-1000, Slovenia (e-mail: uros.cvelbar@ijs.si).

D. Mariotti is with the Nanotechnology and Integrated Bio-Engineering Centre, University of Ulster, Newtownabbey BT37 0QB, U.K. (e-mail: d.mariotti@ulster.ac.uk).

Color versions of one or more of the figures in this paper are available online at http://ieeexplore.ieee.org.

Digital Object Identifier 10.1109/TPS.2013.2295626 of dense plasmas with a narrow ion beam directed to a particular area of the substrate is obtained in the hybrid plasma setup, which combines the arc and planar magnetron. A photo of the magnetron discharge at the gas pressure of $0.5 \mathrm{~Pa}$ is shown in Fig. 1(a). The discharge has a ring structure conditioned by arc-shaped magnetic trap for the electrons. Fig. 1(b) shows the plasma structure produced by the arc source, when the planar magnetron is not operating (i.e., the magnetron discharge was not ignited, but the magnetic field of the magnetron was present). When both sources operate and the magnetic field of the magnetron is directed in-line with the field of the arc source, a bottle configuration of a magnetic trap is formed between the arc source and the substrate. A domain with the excess of the plasma electrons over the ions is generated in the magnetic trap. The ions are affected by a self-consistent electric field, and the plasma flow is focused to a narrow area located right above the magnetic pole of the magnetron, with the ratio $\alpha_{\text {in }}$ of 1 . When increasing the gas pressure up to $0.5 \mathrm{~Pa}$, the plasma configuration is changed, as shown in Fig. 1(c), due to the formation of another domain with the electron excess-in the region of the arc-shaped magnetic trap of the magnetron. The domain is formed by the bulk electrons generated due to ionization of the residual gas by the secondary electrons emitted from the substrate. In this case, the ion flow is directed toward the magnetron trap, while $\alpha_{\text {in }}=0.02$. At the intermediate pressures, the focusing of the ion flow at a fixed level of the gas pressure is possible. The discharge structure for the pressure of $0.1 \mathrm{~Pa}$ $\left(\alpha_{i n}=0.1\right)$ is shown in Fig. 1(d), schematic of the setup is shown in Fig. 1(e), and the measured distribution of the ion current over the substrate is shown in Fig. 1(f). The $\alpha_{\text {in }}$ parameter was estimated by the technique described in detail in [5].

This technique allows generation of narrow and broad ion beams. In addition, depending on the number and location of the magnetic coils, the ion current density can be varied in $\sim 2$ times. Our visualizations also reveal the mechanisms of the plasma interaction with the magnetic fields in reactors, thus enabling a further development of plasma-based technologies for deposition, modifications, and growth of nanostructures for microelectronics, optics, energy, and so on. 

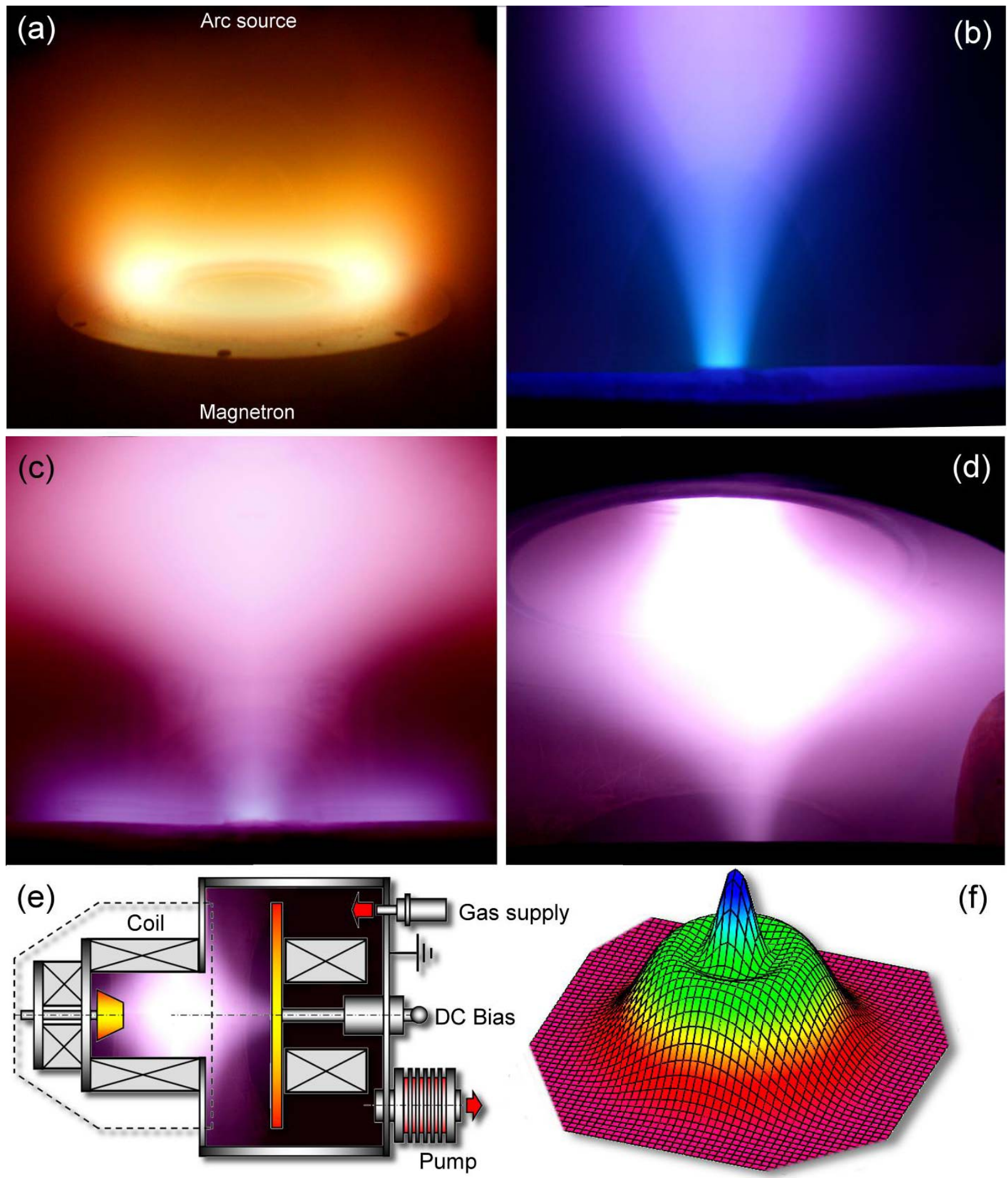

(f)

Fig. 1. Plasma patterns for the different configurations of the magnetic traps. (a) Ring-shaped magnetron discharge generated in the arc-shaped magnetic trap. (b) Powerful jet generated by the bottle-shaped magnetic trap between the arc and the magnetron sources at gas pressure of $0.02 \mathrm{~Pa}$. (c) Tube-shaped plasma jet directed from the bottle trap to the arc-shaped trap. (d) Powerful jet with controlled ion-to-neutral fluxes ratio. (e) Schematic of the setup (rotated counterclockwise by $90^{\circ}$ relative to the discharge photos). (f) 3-D visualization of the measured distribution of the ion current over the substrate for the configuration in (d).

\section{REFERENCES}

[1] M. Keidar and I. I. Beilis, "On a model of nanoparticle collection by an electrical probe," IEEE Trans. Plasma Sci., vol. 38, no. 11, pp. 3249-3251, Nov. 2010.

[2] K. Ostrikov, E. C. Neyts, and M. Meyyappan, "Plasma nanoscience: From nano-solids in plasmas to nano-plasmas in solids," Adv. Phys., vol. 62, no. 2, pp. 113-224, 2013.
[3] R. M. Sankaran, "Towards chirality-controlled SWCNTs: Can a plasma help?" J. Phys. D, Appl. Phys., vol. 44, no. 17, pp. 174005-1-174005-8, 2011.

[4] O. Baranov and M. Romanov, "Process intensification in vacuum arc deposition setups," Plasma Process. Polymers, vol. 6, no. 2, pp. 95-100, 2009.

[5] N. S. J. Braithwaite, "Introduction to gas discharges," Plasma Sour. Sci. Technol., vol. 9, no. 4, pp. 517-537, 2000. 